\title{
Free-standing NiO-MgO nanosheets in-situ controllably composited on Ni-foam as monolithic catalyst for catalytic oxy-methane reforming
}

\author{
Ruijuan Chai, Yakun Li, Qiaofei Zhang, Guofeng Zhao*, Ye Liu, and Yong Lu* \\ Shanghai Key Laboratory of Green Chemistry and Chemical Processes, School of Chemistry and Molecular \\ Engineering, East China Normal University, Shanghai 200062, China.
}

Fax: (+86)21-62233424, E-mail: ylu@chem.ecnu.edu.cn (Y.Lu); gfzhao@chem.ecnu.edu.cn (G.F. Zhao)

\begin{abstract}
Free-standing $\mathrm{NiO}-\mathrm{MgO}$ composite nanosheet catalysts to be used for catalytic oxy-methane reforming (COMR) have been developed by in-situ growing onto the Ni-foam struts under hydrothermal condition followed by calcination treatment. Among them, the $\mathrm{NiO}-\mathrm{MgO} / \mathrm{Ni}$-foam consisting of $1.0 \% \mathrm{MgO}, 18.7 \% \mathrm{NiO}$ and nickel-foam-strut balance is the best structured catalyst engineered from nano- to macro-scale, being capable of converting $82.9 \% \mathrm{CH}_{4}$ into syngas at selectivity of $94.7 \%$ to $\mathrm{H}_{2}$ and of $89.9 \%$ to $\mathrm{CO}$ for a feed of $\mathrm{CH}_{4} / \mathrm{O}_{2}=2 / 1$ (vol/vol), at $700{ }^{\circ} \mathrm{C}$ and a high gas hourly space velocity of $100 \mathrm{~L} \mathrm{~g}^{-1} \mathrm{~h}^{-1}$. Nevertheless, improvement of their carbon resistance and textural stability is particularly desirable.
\end{abstract}

Keywords: microstructure; porous material; structured catalyst; high-throughput catalysis; Ni-foam; catalytic oxy-methane reforming

\section{Introduction}

Methane, which is both the largest constituent of natural gas and one of the most available and affordable feedstocks for the synthesis of fuels and chemicals, can be converted into value-added products by either direct or indirect routes [1,2]. The direct routes are less viable from a commercialization viewpoint due to the limited product-yields originated from the higher product-reactivities than methane; while the indirect routes, with the syngas production process as the prerequisite operation in the indirect methane conversion, are commercially promising because 
syngas can be efficiently converted into various valuable products [3]. However, the well-established methane stream reforming is very energy-intensive and costly because the reaction is highly endothermic and $\mathrm{H}_{2} / \mathrm{CO}$ ratio of 3 is too high for Fischer-Tropch synthesis. Therefore, the cost-effective process for syngas production from methane is particularly desirable but remains challenging, which have aroused the considerable scientific and technological interests [4]. Catalytic oxy-methane reforming (COMR) is an attractive method for the syngas production owing to the compact reactor, high energy-efficiency and favorable $\mathrm{H}_{2} / \mathrm{CO}$ ratio for the downstream processes such as methanol and Fischer-Tropsch synthesis [5].

Ni-based catalysts with moderate cost and excellent performance are commonly recognized to be the most promising candidates for high-throughput COMR process [6-9]. It is urgent but still significantly challenging to delicately design a catalyst with a unique combination of excellent activity, satisfying carbon resistance, distinguished robustness, high thermal conductivity and high permeability for lowering pressure drop. Recently, as the process intensification gradually known, the metal-foam-structured catalysts have attracted ever-increasing interest [10]. Our previous efforts have demonstrated successful applications of the Ni-foam in developing high-performance structured catalysts for COMR [11], syngas methanation [12] and coalbed methane catalytic deoxygenation [13]. It is thus exceptionally worthwhile to develop foam-structured catalyst for such exothermic and high-throughput COMR reaction process [14].

Herein, we demonstrate a monolithic Ni-foam-structured catalyst engineering from micro- to macro-scale, which was obtained by in-situ growing $\mathrm{NiO}-\mathrm{MgO}$ composite nanosheets on the Ni-foam strut surface via hydrothermal reaction followed by calcination treatment. This is a promising approach to provide a unique combination of the attractive ability of the $\mathrm{MgO}$ promoter for suppressing carbon formation and the high permeability and enhanced heat/mass transfer 
stemmed from Ni-foam.

\section{Experimental}

The catalysts were typically prepared by hydrothermal treatment of Ni-foam using aqueous solution containing $\mathrm{Mg}\left(\mathrm{NO}_{3}\right)_{2}$ and $\mathrm{NH}_{4} \mathrm{Cl}$ followed by a calcination process. Corresponding to the $\mathrm{Mg}\left(\mathrm{NO}_{3}\right)_{2}$ concentrations of $0.05 \mathrm{~mol} \mathrm{~L}^{-1}, 0.15 \mathrm{~mol} \mathrm{~L}^{-1}, 0.25 \mathrm{~mol} \mathrm{~L}^{-1}$ and $0.35 \mathrm{~mol} \mathrm{~L}^{-1}$, the resulting catalysts are denoted as Cat-1, Cat-2, Cat-3 and Cat-4, respectively. Details of catalyst preparation, characterization, and evaluation are available in the Supporting material.

\section{Results and discussion}

\subsection{Geometry, morphology and structural features}

Fig. 1 shows the geometry, morphology and structural features of our representative foam-structured catalysts, while their textual properties, $\mathrm{NiO}$ crystallite size as well as $\mathrm{NiO}$ and $\mathrm{MgO}$ contents and the specific surface area (SSA) are collected in Table S1. Fig. 1A and Fig. S1 shows the untreated circular Ni-foam wafers with a diameter of $6 \mathrm{~mm}$ and its interconnected porous framework and zigzag structure. After hydrothermal treatment of Ni-foam using aqueous solution containing $\mathrm{Mg}\left(\mathrm{NO}_{3}\right)_{2}$ and $\mathrm{NH}_{4} \mathrm{Cl}$ with varied $\mathrm{Mg}\left(\mathrm{NO}_{3}\right)_{2}$ concentration from 0.05 to $0.35 \mathrm{~mol} \mathrm{~L}^{-1}$ followed by calcination, as shown in Fig. 1B, the obtained foam-structured catalysts of Cat-1 to Cat-4 all showed formation of $\mathrm{NiO}$ phase (JCPDS no. 78-0429) but not $\mathrm{MgO}$ phase clearly evidenced by XRD patterns at $2 \theta$ of $37.3^{\circ}, 43.3^{\circ}, 62.9^{\circ}, 75.4^{\circ}$ and $79.4^{\circ}$. For comparison, a pristine $\mathrm{Ni}$-foam circular chip was calcined merely in air for $2 \mathrm{~h}$ at $450{ }^{\circ} \mathrm{C}$ and XRD measurement showed no formation of $\mathrm{NiO}$ phase, in turn confirming that the $\mathrm{NiO}$ phase detectable on the above four catalysts was formed by hydrothermal/calcination treatment process. Moreover, the average grain size of $\mathrm{NiO}$ for these four catalysts were estimated all to be $\sim 18 \mathrm{~nm}$ by using Scheere's equation (Table S1). Notably, the XRD peak intensity of $\mathrm{NiO}$ increased with increasing $\mathrm{Mg}\left(\mathrm{NO}_{3}\right)_{2}$ and 
$\mathrm{NH}_{4} \mathrm{Cl}$ concentrations in the hydrothermal process, suggesting an increased content of $\mathrm{NiO}$ on the Ni-foam surface. Indeed, based on the $\mathrm{H}_{2}$ consumption in $\mathrm{H}_{2}$-TPR experiments, the $\mathrm{NiO}$ contents were estimated to be $8.1 \%, 11.9 \%, 18.7 \%$ and $21.2 \%$ for Cat- 1 , Cat-2, Cat-3 and Cat- 4 , while the corresponding $\mathrm{MgO}$ contents were determined by ICP-AES to be $0.3 \%, 0.5 \%, 1.0 \%$ and $1.1 \%$ (Table S1). In addition, SEM images in Fig. 1C-F showed that the formed $\mathrm{NiO}$ existed in the form of nanosheets (30-200 $\mathrm{nm}$ in thickness) in their ab-direction disorderedly perpendicular to the strut surface of the Ni-foam substrate. The nanosheets became thinner gradually with increasing the concentrations of $\mathrm{Mg}\left(\mathrm{NO}_{3}\right)_{2}$ and $\mathrm{NH}_{4} \mathrm{Cl}$. Interestingly, likely owing to the gas release during the decomposition of the metal hydroxide precursors, lots of uniform mesopores were formed in the nanosheets with diameter of ca. 10-20 nm (high-magnitude SEM images inserted in Fig. 1C-F). And the hysteresis loops in Fig. S2 also indicated the mesoporous features and the average pore dimeters were further more precisely determined to be $12 \mathrm{~nm}, 12 \mathrm{~nm}, 19 \mathrm{~nm}$ and $25 \mathrm{~nm}$ for Cat-1, Cat-2, Cat-3 and Cat-4. Moreover, associated with the formation of the MgO-modified NiO nanosheets, the $\mathrm{N}_{2}$-Brunauer-Emmett-Teller SSA of the catalyst products increased obviously to $5-8 \mathrm{~m}^{2} / \mathrm{g}$ from only $1.0 \mathrm{~m}^{2} \mathrm{~g}^{-1}$ for the pristine Ni-foam (Table $\mathrm{S} 1$ ).

\subsection{Catalyst performance for COMR}

As shown in Fig. S3, the four catalysts all were active and selective for the COMR reaction in the temperature range studied, being undoubtedly contributed to the $\mathrm{NiO}-\mathrm{MgO}$ nanosheets embedded into the Ni-foam structure (Fig. 1). Over each of the four catalysts, the methane conversion and syngas selectivity increased concomitantly along with the increase of reaction temperature from 600 to $800{ }^{\circ} \mathrm{C}$ (Fig. S3). Notably, oxygen was totally consumed in the whole reaction temperature range for all catalysts. It is widely accepted that the COMR proceeds via catalytic methane combustion and subsequent steam/ $\mathrm{CO}_{2}$ reforming of methane [5]. The SRM and 
DRM reactions are both strongly endothermic and favorable at elevated reaction temperature. This is the reason that the activity/selectivity of our foam-structured NiO-MgO nanosheet catalysts for the COMR reaction is promoted with increasing the reaction temperature. For a reference, the pristine Ni-foam calcined at $450{ }^{\circ} \mathrm{C}$ was also tested and showed poor activity for the COMR reaction, delivering a limited $\mathrm{CH}_{4}$ conversion of below $10 \%$ even at $800{ }^{\circ} \mathrm{C}$.

Fig. S3 also shows that the Cat-3 and Cat-4 catalysts demonstrated comparable methane conversion and syngas selectivity but higher than the Cat-1 and Cat-2 catalysts at each reaction temperature. At a low reaction temperature of $600{ }^{\circ} \mathrm{C}$, the methane conversion of $\sim 75 \%$ could be obtained with $\sim 91 \% / 84 \%$ selectivity to $\mathrm{H}_{2} / \mathrm{CO}$ over the Cat-3 and Cat-4 catalysts, while relatively low methane conversion of $\sim 70-72 \%$ could be achievable with $89-90 \% / 80-82 \%$ selectivity to $\mathrm{H}_{2} / \mathrm{CO}$ over the Cat- 1 and Cat-2 catalysts. At a high reaction temperature of $800{ }^{\circ} \mathrm{C}$, the Cat-3 and Cat-4 catalysts delivered $\mathrm{CH}_{4}$ conversion of $\sim 89 \%$ and $\sim 96 \% / \sim 95 \%$ selectivity to $\mathrm{H}_{2} / \mathrm{CO}$, being much higher than those $84-85 \%$ conversion and $\sim 94 \% / 92-93 \%$ selectivity to $\mathrm{H}_{2} / \mathrm{CO}$ over the Cat-1 and Cat- 2 catalysts. As shown in Table S1, the Cat-1 and Cat-2 catalysts possessed relatively low $\mathrm{NiO}$ contents $(8.1 \%$ for Cat- $1,11.9 \%$ for Cat- 2$)$ compared to the high $\mathrm{NiO}$ contents of $19-21 \%$ for the Cat-3 and Cat-4. Taking into account of the almost identical NiO size and SSA (Table S1), it is clear that the activity/selectivity of our foam-structured $\mathrm{NiO}-\mathrm{MgO}$ nanosheet catalysts was correlated well with their $\mathrm{NiO}$ contents which was closely related to the hydrothermal condition.

\subsection{Stability and carbon resistance}

Fig. S4 shows the methane conversion and syngas selectivity for the COMR reaction against time on stream using the Cat- 3 catalyst at $700{ }^{\circ} \mathrm{C}$ and a GHSV of $100 \mathrm{~L} \mathrm{~g}^{-1} \mathrm{~h}^{-1}$. The testing was lasted for $30 \mathrm{~h}$ while the catalyst activity/selectivity showed a continuous decline trend. The methane conversion decreased from $82.9 \%$ to $74.7 \%$ while the selectivity to $\mathrm{H}_{2} / \mathrm{CO}$ decreased from 
$94.7 \% / 89.9 \%$ to $89.1 \% / 87.9 \%$ within $30 \mathrm{~h}$ on stream. The testing was thus terminated and the catalyst deactivation was tentatively studied. Fig. S5 shows the XRD pattern of the Cat-3 after 30-h test, clearly indicating the characteristic diffraction peak of graphite carbon (JCPDS no. 89-8487). The carbon deposition was also imaged by SEM (Fig. S6A) and its amount was measured by TGA with the profiles as shown in Fig. S7. In accordance, the carbon amount on the tested catalyst was

estimated to be $0.3 \mathrm{~g}_{\mathrm{car}} \mathrm{g}_{\mathrm{cat}}{ }^{-1}$ (corresponding to a coking rate of $0.01 \mathrm{~g}_{\mathrm{car}} \mathrm{g}_{\mathrm{cat}}{ }^{-1} \mathrm{~h}^{-1}$ ). As previously reported [15,16], the modification of $\mathrm{MgO}$ could prohibit the carbon deposition of the Ni-based catalyst, and accordingly, the severe carbon deposition may be due to the low $\mathrm{MgO}$ content in our present catalyst. In addition, the sintering of free-standing NiO-MgO nanosheets was also clearly imaged by SEM (Fig. S6B). After burning off the carbon deposit at $600{ }^{\circ} \mathrm{C}$ for $1 \mathrm{~h}$ in air, the SSA was reduced to $1.8 \mathrm{~m}^{2} \mathrm{~g}^{-1}$ (a fourth of that for the fresh Cat-3, Table S1), further confirming the sintering of NiO-MgO nanosheets. The above results suggested that the coking and the sintering of the $\mathrm{NiO}-\mathrm{MgO}$ nanosheets were the main causes for the quick deactivation.

\section{Conclusions}

Free-standing NiO-MgO nanosheet catalysts are successfully engineered from nano- to macro-scale by in situ growth of them onto a Ni-foam substrate via hydrothermal/calcination treatment. Cat-3 with $1.0 \% \mathrm{MgO}, 18.7 \% \mathrm{NiO}$ and nickel-foam-strut balance is the best structured catalyst, being capable of converting $82.9 \% \mathrm{CH}_{4}$ into syngas at selectivity of $94.7 \%$ to $\mathrm{H}_{2}$ and of $89.9 \%$ to $\mathrm{CO}$ for a feed of $\mathrm{CH}_{4} / \mathrm{O}_{2}=2 / 1$ (vol/vol), at $700{ }^{\circ} \mathrm{C}$ and a high GHSV of $100 \mathrm{~L} \mathrm{~g}^{-1} \mathrm{~h}^{-1}$. Despite the promising results, the improvement of their anti-sintering stability as well as carbon resistance is particularly desirable and remains challenging.

\section{Acknowledgments}

This work was financially supported by the NSF of China $(21473057$, U1462129, 21273075) and the 
“973 program” (2011CB201403) from the MOST of China.

\section{References}

[1] P. Tang, Q.J. Zhu, Z.X. Wu, D. Ma, Energy Environ. Sci. 7 (2014) 2580-2591.

[2] A. Caballero, P.J. Perez, Chem. Soc. Rev. 42 (2013) 8809-8820.

[3] T.V. Choudhary, A.E. Aksoylu, D.W. Goodman, Catal. Rev. Sci. Eng. 45 (2003) 151-203.

[4] L.L. Makarshin, V.A. Sadykov, D.V. Andreev, A.G. Gribovskii, V.V. Privezentsev, V.N. Parmon, Fuel Process. Technol. 131 (2015) 21-28.

[5] T.V. Choudhary, V.R. Choudhary, Angew. Chem. Int. Ed. 47 (2008) 1828-1847.

[6] H.M. Liu, D.H. He, Catal. Surv. Asia 16 (2012) 53-61.

[7] Y. Lu, Y. Liu, S.K. Shen, J. Catal. 177 (1998) 386-388.

[8] Y. Lu, J.Z. Xue, C.C. Yu, Y. Liu, S.K. Shen, Appl. Catal. A 174 (1998) 121-128.

[9] L. Chen, Y. Lu, Q. Hong, J. Lin, F.M. Dautzenberg, Appl. Catal. A 292 (2005) 295-304.

[10] J.P. Bortolozzi, L.B. Gutierrez, M.A. Ulla, Appl. Catal. A 452 (2013) 179-188.

[11] R.J. Chai, Y.K. Li, Q.F. Zhang, G.F. Zhao, Y. Liu, Y. Lu, Catal. Commun. 70 (2015) 1-5.

[12] Y.K. Li, Q.F. Zhang, R.J. Chai, G.F. Zhao, Y. Liu, Y. Lu, ChemCatChem 7 (2015) 1427-1431.

[13] Q.F. Zhang, X.P. Wu, G.F. Zhao, Y.K. Li, C.Z. Wang, Y. Liu, X.Q. Gong, Y. Lu, Chem. Commun. 51 (2015) 12613.

[14] G. Groppi, A. Beretta, E. Tronconi, Monolithic catalysts for gas-phase synthesis of chemicals, in: A. Cybulski, J. A. Moulijn (Eds.), Structured catalysts and reactors (2nd edition), CRC Press Taylor \& Francis Group, Boca Raton, 2006, pp. 243-310.

[15] H. Ozdemir, M.A.F. Oksuzomer, M.A. Gurkaynak, Int. J. Hydrogen Energy 35 (2010) 12147-12160.

[16] H. Milberg, A. Juan, N. Amadeo, B. Irigoyen, J. Mol. Catal. A: Chem. 35 (2010) 171. 


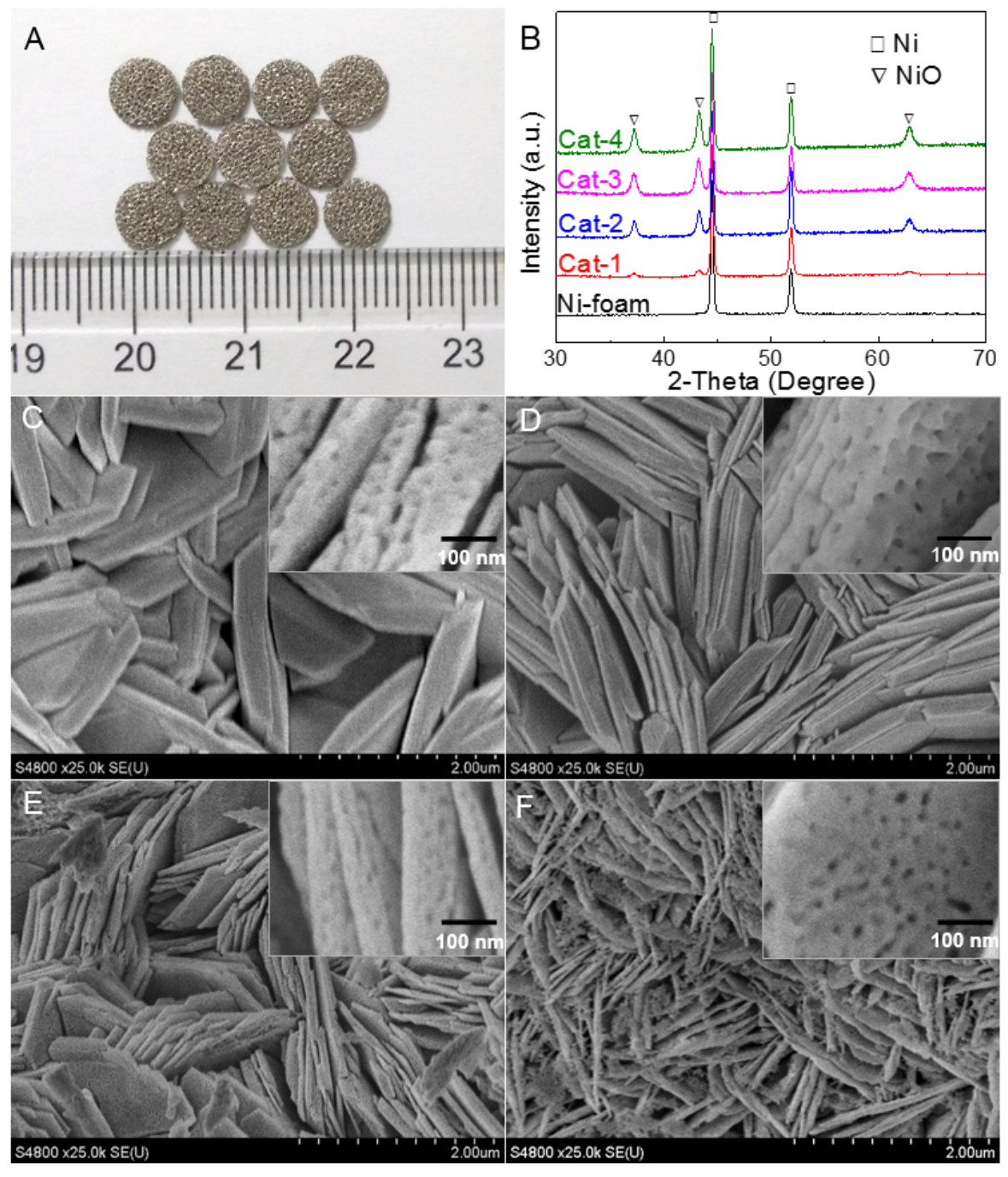

Fig. 1. The photograph (A) of the untreated monolithic Ni-foam wafers. (B) XRD patterns of the as-prepared $\mathrm{NiO}-\mathrm{MgO} / \mathrm{Ni}$-foam catalysts and $\mathrm{Ni}$-foam substrate calcined at $450{ }^{\circ} \mathrm{C}$ in air for $2 \mathrm{~h}$. SEM images of the fresh catalysts: Cat-1 (C), Cat-2 (D), Cat-3 (E) and Cat-4 (F). 


\section{Graphic abstract}

Free-standing NiO-MgO composite nanosheet catalysts to be used for catalytic oxy-methane reforming (COMR) has been developed by in-situ growing onto the $\mathrm{Ni}$-foam struts under hydrothermal condition followed by calcination treatment.

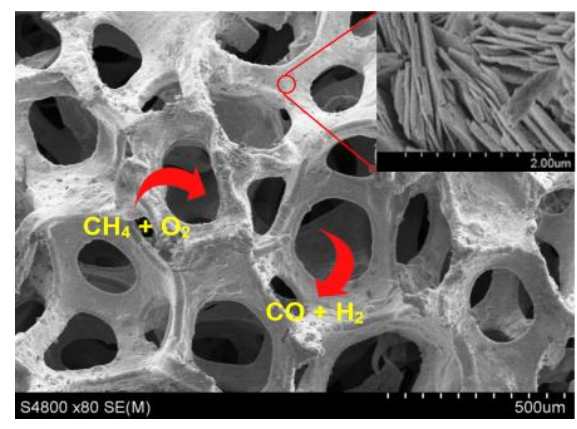

